\title{
RKIP inhibits the malignant phenotypes of gastric cancer cells
}

\author{
X. M. ZHANG, H. GU, L. YAN, G. Y.ZHANG* \\ Department of Gastroenterology, Xiangya Hospital, Central South University, Changsha, Hunan 410008, China \\ ${ }^{*}$ Correspondence: guiyingzhang1@126.com
}

Received July 16, 2012/ Accepted September 25, 2012

\begin{abstract}
Raf kinase inhibitor protein (RKIP) is first identified as an interacting partner of Raf-1. RKIP expression is low or absent in several established cell lines derived from metastatic breast cancer, prostate cancer and melanoma cells. However, the functional role of RKIP in gastric cancer remains unclear. In this study, we employed human gastric cancer cell line SGC7901 as a model to reconstitute RKIP expression in gastric cancer cells. The growth curve and soft agar assay showed that RKIP inhibited the growth and clonogenicity of SGC7901 cells. Flow cytometry analysis showed that RKIP inhibited the cell cycle progression and induced the apoptosis of SGC7901 cells. Wound healing and transwell invasion assay showed that RKIP inhibited the migration and invasion of SGC7901 cells. Furthermore, we observed that RKIP inhibited the growth of SMGC7901 cells in xenografts in nude mice. Taken together, our in vitro and in vivo data demonstrate that RKIP modulates the proliferation, apoptosis, migration, invasion and tumorigenicity of SGC7901 cells. These results reveal the tumor suppressor role of RKIP in gastric cancer and suggest that RKIP may be new therapeutic target for gastric cancer.
\end{abstract}

Key words: gastric cancer, RKIP, Raf, tumor suppressor, SGC7901, apoptosis

In the last decade, great progress has been made in the treatment of patients with gastric cancer, one of the most prevalent malignancies in Asia [1]. However, a significant percentage of gastric cancer patients fail to achieve complete remission, leading to the relapse or poor prognosis [2]. Metastasis has been regarded as an important mechanism underlying tumor relapse after successful surgical resections [3-5]. Metastasis is the advanced stage of solid tumor progression and is a multistep process that involves invasion, intravasation, extravasation to distant organs and final growth of the secondary tumor. A group of genes, termed metastasis suppressor genes (MSGs), encode for proteins that inhibit various steps of the metastatic cascade [6].

Raf kinase inhibitor protein (RKIP) is one of the MSGs that suppress metastasis. RKIP is first identified as an interacting partner of Raf- 1 and as a negative regulator of mitogen-activated protein kinase (MAPK) pathway downstream of Raf-1 [7]. RKIP expression is low or absent in several established cell lines derived from metastatic breast cancer, prostate cancer and melanoma cells. Moreover, loss of RKIP has been shown to promote tumor development by conferring radioresistance and chemoresistance [8]. However, the functional role of RKIP in gastric cancer remains unclear.
Our preliminary study showed that RKIP expression was low in gastric cancer tissues compared to adjacent normal gastric tissues [9]. Therefore, in this study we used gastric cancer cell line SGC7901 cells as a model to investigate whether and how the loss of RKIP contributes to gastric cancer development. Our results demonstrated that reconstitution of RKIP inhibited the proliferation, clonogenicity, migration and invasion of SGC7901 cells in vitro, and induced the apoptosis of SGC7901 cells in vitro. Furthermore, we validated that RKIP inhibited the tumorigenicity in vivo, thus confirming the tumor suppressor role of RKIP in gastric cancer.

\section{Materials and methods}

Cell culture and transfection. SGC7901 cell line was obtained from the Institute of Biochemistry and Cell Biology, Chinese Academy of Sciences (Shanghai, China) and cultured in RPMI-1640 medium (Gibco, USA) supplemented with $10 \%$ fetal calf serum (Hyclone, USA) at $37^{\circ} \mathrm{C}$ in $5 \% \mathrm{CO}_{2}$. The cells were transfected with pcDNA3.1(+)-RKIP [9] or control pcDNA3.1(+)constructs using Lipofectime 2000 (Invitrogen, Carlsbad, CA, USA) following the manufacturer's instruction. Two days after trnasfection, the cells were selected with 500 
$\mu \mathrm{g} / \mathrm{mL}$ G418 (Promega, Madison, WI, USA) for 8 days to get SGC7901 derived stable cell lines as follows: pcDNA3.1(+)RKIP/SGC7901 (transfected with pcDNA3.1(+)-RKIP vector); pcDNA3.1(+)/SGC7901 (transfected with pcDNA3.1(+) empty vector).

Reverse-transcription PCR. Total RNA was isolated from SGC7901 and derived cells using Trizol (Invitrogen, Carlsbad, CA, USA) according to the manufacturer's protocol. cDNA was prepared using Reverse Transcription System (Promega, Madison, WI, USA). Quantitative reverse-transcription PCR was performed using SYBR Premix Ex Taq (TaKaRa, Dalian, China). The primers were as follows: for RKIP, forward 5'-ATAGACCCACCAGCATTTCG-3' and reverse 5'-ACTGTGCCACTGCTGATGTC-3' (amplicon 163 bp); for GAPDH, forward 5'-CCACCCATGGCAAATTCCATGGCA-3' and reverse 5'-GGTGGACCTGACCTGCCGTCTAGA-3' (amplicon $598 \mathrm{bp}$ ). Amplification conditions were as follows: $3 \mathrm{~min}$ at $95^{\circ} \mathrm{C}$ (one cycle) and $30 \mathrm{sec}$ at $95^{\circ} \mathrm{C} ; 30 \mathrm{sec}$ at $50^{\circ} \mathrm{C}$ and $30 \mathrm{sec}$ at $72^{\circ} \mathrm{C}$ ( 40 cycles) and $72^{\circ} \mathrm{C}$ for $5 \mathrm{~min}$ (one cycle). GAPDH was used as internal control. The experiment was independently repeated three times.

Western blotting analysis. When SGC7901 and derived cells grew to $70-80 \%$ confluence, they were lysed and the total cell extracts were separated by $12 \%$ SDS-PAGE, transferred onto nitrocellulose membranes, then probed with rabbit anti-human RKIP antibody (1:500, Santa Cruz Biotechnology, Santa Cruz, CA, USA) or $\beta$-actin antibody (1:1000, Santa Cruz Biotechnology, Santa Cruz, CA, USA) overnight at $4{ }^{\circ} \mathrm{C}$. The membrane was washed with TBST for four times ( $5 \mathrm{~min} / \mathrm{each}$ time), then incubated with goat anti-rabbit alkaline phosphatase conjugated secondary antibody (1:1000, Santa Cruz Biotechnology, Santa Cruz, CA, USA) for $1 \mathrm{~h}$ at room temperature. Finally, the membrane was developed using ECL kit (Pierce, Rockford, IL, USA) and exposed to X-ray film.

Cell growth curve assay. SGC7901 and the derived cells were trypsinized and seeded into 6-well plates at $1 \times 10^{4}$ cells/ well for further culture (in triplicate). The viable cells were counted on a hemacytometer each day for 7 days. The cell growth curve was drawn based on the counting.

TUNEL assay. TUNEL assay was performed using TUNEL Kit (Promega, Madison, WI, USA) following the manufacturer's instruction. Briefly, SGC7901 and the derived cells were cultured and then fixed using $10 \%$ formalin followed by washing with phosphate buffer saline (PBS). Cells were then permeabilized using $0.2 \%$ triton X-100. Biotinylated dUTP in rTdT reaction mixture was added to label the fragmented DNA at $37^{\circ} \mathrm{C}$ for $1 \mathrm{~h}$ in the dark, followed by blocking endogenous peroxidases with $0.3 \%$ hydrogen peroxide. Streptavidin HRP (1:500 in PBS) was added and incubated at room temperature for $30 \mathrm{~min}$. Finally, hydrogen peroxide and chromagen diaminobenzidine were used to visualize nuclei with fragmented DNAs under the light microscope. TUNEL-positive cells were expressed as a percentage of apoptotic cells in total cells in the microscopic field.
Soft agar assay. SGC7901 and the derived cells were suspended in $0.3 \%$ agarose in RPMI-1640 medium supplemented with $10 \%$ fetal calf serum, plated at a density of $2 \times 10^{4}$ cells in a $60-\mathrm{mm}$ dish coated previously with $0.6 \%$ agarose, and maintained at $37 \mathrm{C}^{\circ}$ in $5 \% \mathrm{CO}_{2}$. On day 14 , colonies $>0.2 \mathrm{~mm}$ in diameter were counted and analyzed.

Wound healing assay. SGC7901 and the derived cells were were grown to confluence in 6-well plate, then the cell monolayer was scraped in a straight line by a 10 -ul pipette tip. The cells were washed twice with PBS and incubated in RPMI-1640 medium supplemented with 5\% fetal calf serum at $37 \mathrm{C}^{\circ}$ in $5 \% \mathrm{CO}_{2}$. The pictures were taken at $18 \mathrm{~h}$ after the scratches by Nikon microscope.

Transwell invasion assay. Cell invasion assay was performed using transwell chamber $(8.0 \mu \mathrm{m}$ pore size, Costar, Cambridge NY, USA). BD Matrigel was added to the upper membrane and allowed to gel for $1 \mathrm{~h}$ at $37^{\circ} \mathrm{C}$. Then $500 \mu \mathrm{l}$ medium containing chemotactic factor was placed in the lower chamber. SGC7901 and the derived cells were plated in the upper chamber at a density of $2 \times 105 / \mathrm{ml}$ and incubated at $37^{\circ} \mathrm{C}$ for $36-48 \mathrm{~h}$. Cells were then fixed with paraformaldehyde, stained with crystal violet, and the number of migrated cells on the lower surface of the membrane was counted under a microscope in eight fields $(200 \times)$. Experiments were repeated three times.

Cell cycle and apoptosis analysis. Flow cytometry analysis was performed to assess the cell cycle phase distribution and apoptosis. SGC7901 and the derived cells were harvested and fixed in 70\% ethanol. After washing with PBS, the cells were resuspended in PBS at the density of $1 \times 10^{6} / \mathrm{ml}$ and treated with RNase A (100 mg/ml PBS) at $37^{\circ} \mathrm{C}$ for $30 \mathrm{~min}$. Next, the cells were resuspended in propidium iodide $(50 \mathrm{mg} / \mathrm{ml} \mathrm{PBS})$ and stained at room temperature for $30 \mathrm{~min}$. Labeled cells were analyzed using FACSort flow ctometry (Beckman Coulter). The results were analyzed using Cell Quest software. Each experiment was repeated three times.

Xenografts in nude mice. Nine athymic nude mice (BALB/ c-nu, 5-week old) were provided by Animal Center of Central South University (Changsha, China). SGC7901 and the derived cells were resuspended in PBS and $3 \times 10^{6}$ cells were injected subcutaneously into the right side of nude mice and the tumor growth was examined. Mice were sacrificed after 6 weeks and tumor metastasis was examined. The tumors were dissected for histological analysis and the measurement of tumor weight.

Statistical analysis. Data were expressed as the mean \pm standard deviation from at least three independent experiments and analyzed by using SPSS 17.0 software (SPSS Inc, IL, USA). Differences between groups were analyzed by using ANOVA test. $P$ value less than 0.05 was considered statistically significant.

\section{Results}

Establishment of stable SGC7901 cells overexpressing RKIP. To reconstitute RKIP expression in gastric cancer cells, 
A
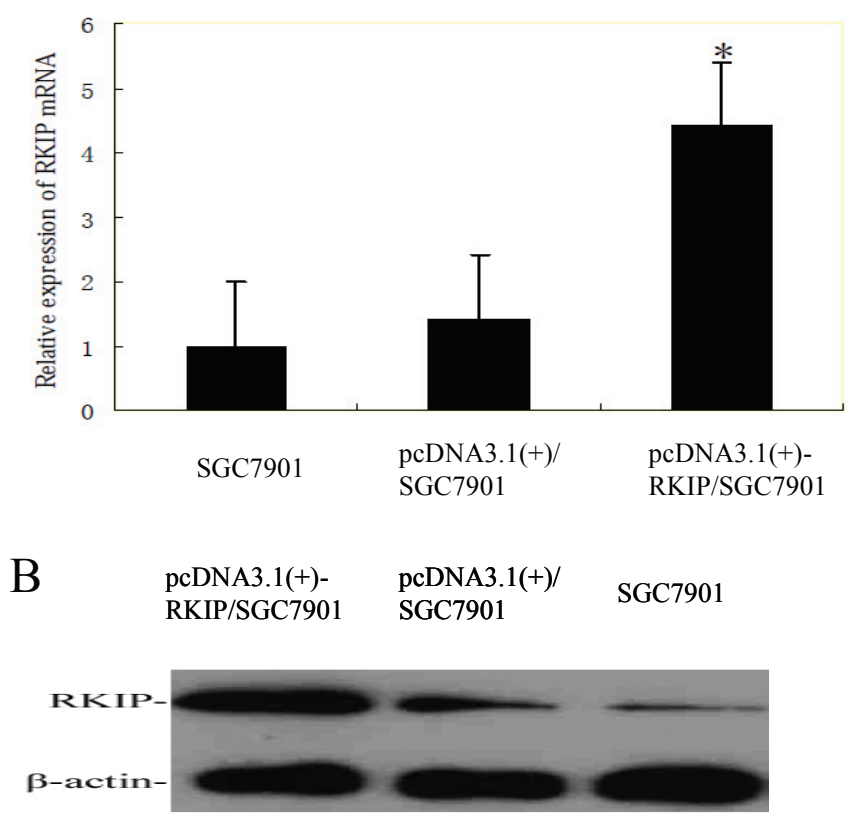

Figure 1. The reconstitution of RKIP expression in SGC7901 cells. A. The relative mRNA level of RKIP in pcDNA3.1(+)-RKIP/SGC7901, pcDNA3.1(+)/SGC7901 and SGC7901 cells was determined by RT-PCR $(\mathrm{n}=3) .{ }^{\star} \mathrm{P}<0.01$ vs. SGC7901 and pcDNA3.1(+)/SGC7901 cells. $\mathrm{B}$. The relative protein level of RKIP in pcDNA3.1(+)-RKIP/SGC7901, pcDNA3.1(+)/ SGC7901 and SGC7901 cells was determined by Western blot analysis. $\beta$-actin served as loading control. Shown were representative blots from three independent experiments with similar results.

SGC7901 cells were transfected with either RKIP expression vector pcDNA3.1(+)-RKIP or pcDNA3.1(+) empty vector as the control. After selection of stable cell lines with G418, Reverse-transcription PCR and Western blot analysis were performed to examine RKIP expression at both mRNA and protein levels in SGC7901 derived cells. RT-PCR analysis showed that the relative mRNA level of RKIP was significantly higher in pcDNA3.1(+)-RKIP/SGC7901 cells than in pcDNA3.1(+)/SGC7901 and SGC7901 cells (Fig. 1A). Moreover, Western blot analysis showed that protein level of RKIP was significantly higher in pcDNA3.1(+)-RKIP/SGC7901 cells than in pcDNA3.1(+)/SGC7901 and SGC7901 cells (Fig. 1B). When summarizing, these data confirm the reconstitution of RKIP expression in SGC7901 cells, which were next utilized for in vitro and in vivo studies to investigate the inhibitory effects of RKIP on gastric cancer growth and metastasis.

RKIP inhibits the growth and induces the apoptosis of SGC7901 cells. To investigate the role of RKIP in the growth of gastric cancer cells, we performed cell growth curve assay of SGC7901 and derived cells. The results showed that the reconstitution of RKIP in SGC7901 cells significantly inhibited cell growth (Fig. 2A). Furthermore, soft agar assay showed that the reconstitution of RKIP in SGC7901 cells significantly inhibited the clonogenicity of SGC-7901 cells (Fig. 2B, p < 0.05 compared to SGC7901 and pcDNA3.1(+)/SGC7901 cells). These data provide strong evidence that RKIP inhibits gastric cancer cell growth.

Next we examined the effects of RKIP on the cell cycle progression and apoptosis of SGC7901 cells. As shown in Fig. 2C, flow cytometry analysis demonstrated that the percentage of cells in G0 and G1 phase was $70.84 \pm 1.37 \%$ in pcDNA3.1(+)-RKIP/SGC7901 cells, higher than that in pcDNA3.1(+)/SGC7901 cells $(63.49 \pm 0.49 \%)$ and SGC7901 cells $(62.55 \pm 0.91 \%)$. In contrast, the percentage of cells in G2 and $M$ phase was $8.43 \pm 1.64 \%$ in pcDNA3.1(+)-RKIP/SGC7901 cells, significantly lower than that in pcDNA3.1(+)/SGC7901 cells $(11.84 \pm 0.23 \%)$ and SGC7901 cells $(14.96 \pm 2.36 \%)$ $(\mathrm{P}<0.05)$. In addition, the apoptosis index was $4.10 \pm 0.51 \%$ in pcDNA3.1(+)-RKIP/SGC7901 cells, significantly higher than that in pcDNA3.1(+)/SGC7901 cells $(1.17 \pm 0.87 \%)$ and SGC7901 cells $(0.79 \pm 0.29 \%)(\mathrm{P}<0.05)$.

To further confirm that RKIP induces the apoptosis of SGC7901 cells, we performed TUNEL assay. The results showed that the percentage of apoptotic cells was $14 \pm 0.99 \%$ for pcDNA3.1(+)-RKIP/SGC7901 cells, significantly higher than that in SGC7901 cells $(2 \pm 0.31 \%)$ and pcDNA3.1(+)/SGC7901 cells $(3 \pm 0.46 \%)(\mathrm{P}<0.05$, Fig. $2 \mathrm{D})$. Taken together, these data suggest that RKIP inhibits the growth and induces the apoptosis of gastric cancer cells.

RKIP inhibits the migration and invasion of SGC7901 cells. We performed wound healing assay to examine the effect of RKIP on the migration ability of gastric cancer cells. $18 \mathrm{~h}$ after the scratch, the width of the scratch was $2.91 \pm 0.21 \mathrm{~mm}$ in pcDNA3.1(+)-RKIP/SGC7901 cells, significantly higher than that in pcDNA3.1(+)/SGC7901 cells $(1.31 \pm 0.34 \mathrm{~mm})$ and SGC7901 cells $(1.26 \pm 0.41 \mathrm{~mm})(\mathrm{P}<0.05$, Fig. $3 \mathrm{~A})$. Next we performed Transwell invasion assay to examine the effect of RKIP on the invasion ability of gastric cancer cells. The results showed that the number of cells invaded the membrane was $107 \pm 20.05$ in pcDNA3.1(+)-RKIP/SGC7901 cells, significantly less than that of pcDNA3.1(+)/SGC7901 cells $(256.5 \pm 37)$ and SGC7901 cells $(276.5 \pm 40)(\mathrm{P}<0.05$, Fig. $3 \mathrm{~B})$. Collectively, these results suggest that RKIP inhibits the migration and invasion of gastric cancer cells.

RKIP inhibits the growth of xenografted SGC7901 cells in vivo. To provide in vivo evidence that RKIP inhibits gastric cancer growth, we employed nude mice model xenograft in which SGC7901 and derived cells were injected subcutaneously. We observed that visual tumor developed 7 days in average after the injection in pcDNA3.1(+)/SGC7901 and SGC7901 groups, but developed 21 days in average after the injection in pcDNA3.1(+)-RKIP/SGC7901 group. The tumors were dissected 6 weeks after the injection and their weight was significant less in pcDNA3.1(+)-RKIP/SGC7901 group $(7.36 \pm 2.10 \mathrm{~g})$ than in pcDNA3.1(+)/SGC7901 group $(13.63 \pm 1.61 \mathrm{~g})$ and SGC7901 group $(14.03 \pm 3.51 \mathrm{~g})(\mathrm{P}<0.05$, Fig. 4A). In addition, tumor growth curve assay showed that transfection of RKIP expression plasmid inhibited the growth 


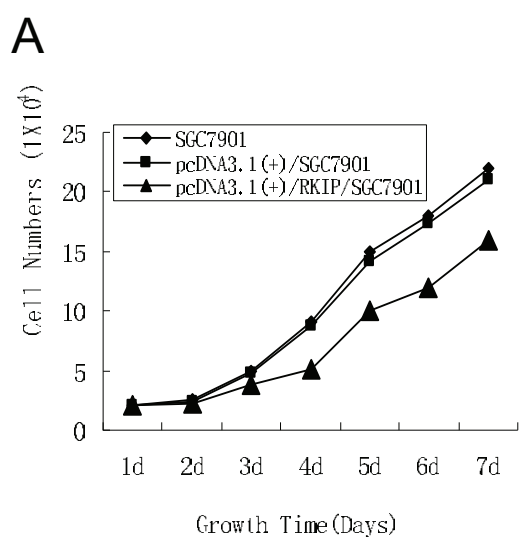

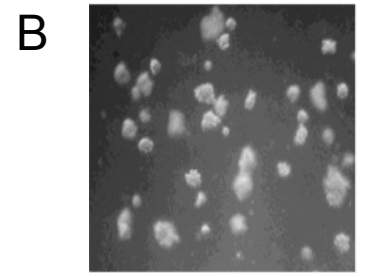

SGC7901

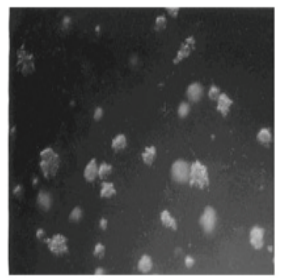

pcDNA3.1(+)/SGC7901

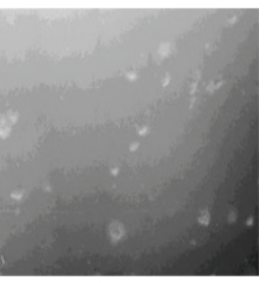

pcDNA3.1(+)-RKIP/SGC7901

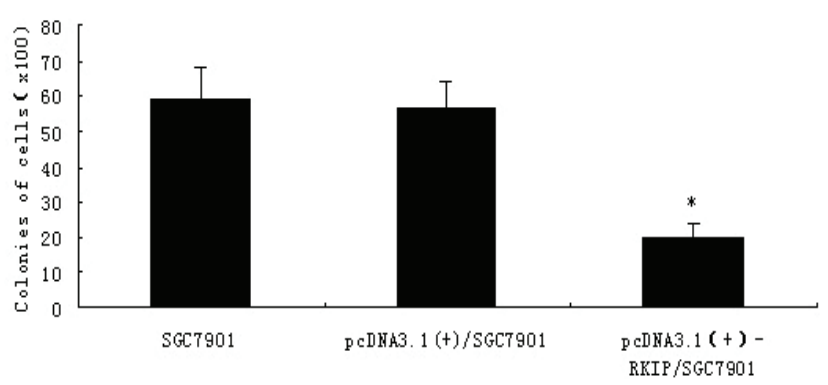

$\mathrm{D}$
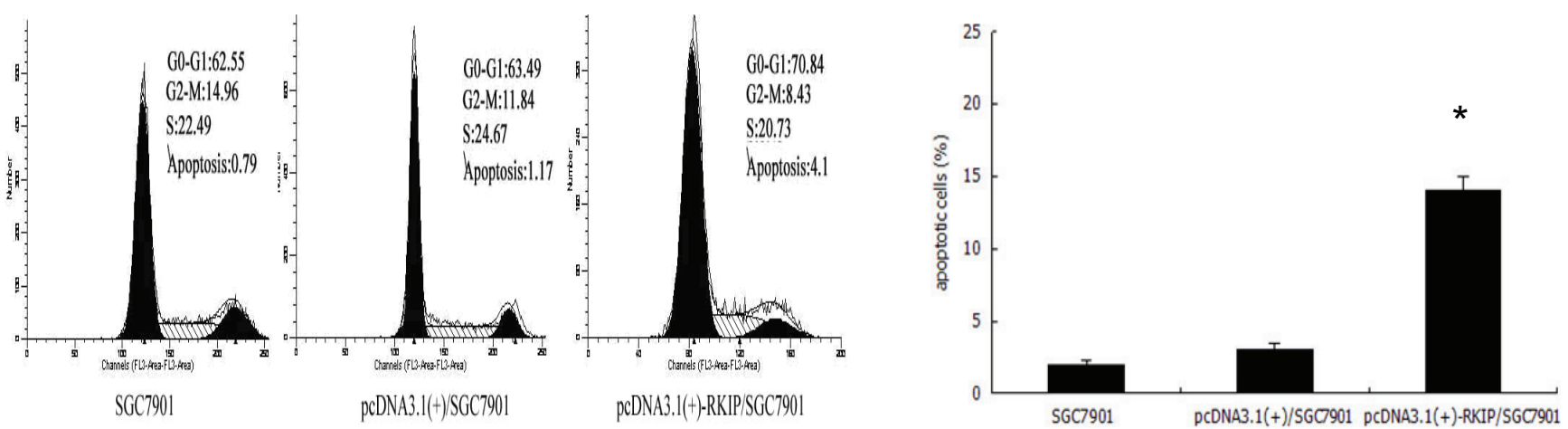

Figure 2. RKIP inhibits the growth and induces the apoptosis of SGC-7901 cells. A. Cell growth curve assay showing the growth of pcDNA3.1(+)-RKIP/ SGC7901, pcDNA3.1(+)/SGC7901 and SGC7901 cells. B. Soft agar assay showing the clonogenicity of pcDNA3.1(+)-RKIP/SGC7901, pcDNA3.1(+)/ SGC7901 and SGC7901 cells. The colonies were counted on day 14 and calculated $(n=3) .{ }^{*} p<0.05$ vs. pcDNA3.1 $(+) / S G C 7901$ and SGC7901 cells. C. Representative flow histograms showing the cell cycle profiles and apoptosis index of pcDNA3.1(+)-RKIP/SGC7901, pcDNA3.1(+)/SGC7901 and SGC7901 cells $(n=3)$. D. TUNEL assay showing the percentage of apoptotic cells in SGC7901, pcDNA3.1(+)/SGC7901, and pcDNA3.1(+)-RKIP/SGC7901 cells $(\mathrm{n}=3) .{ }^{*} \mathrm{p}<0.05$ vs. pcDNA3.1(+)/SGC7901 and SGC7901 cells.

of xenografted SGC7901 cells (Fig. 4B). These data provide evidence that RKIP inhibits gastric tumor growth in vivo.

\section{Discussion}

RKIP is a $20-25 \mathrm{kDa}$ globular protein protein that was originally isolated as an interacting partner of Raf- 1 which negatively regulates MAPK signaling downstream of Raf-1 [7]. MAPK signaling plays important role in coordinating cell survival, proliferation, apoptosis and cell invasion in response to growth factors or drug treatment, and is frequently overactivated in a variety of cancers including gastric cancer [10]. MAPK signaling is well known to be negatively regulated by several regulators such as protein tyrosine phosphatase. RKIP is a newly identified negative regulator of MAPK signaling and it is not surprising that RKIP is downregulated in different types of cancer [11-14]. Especially, recent studies reported that RKIP expression was lower in gastric carcinoma than in normal gastric tissue and loss of RKIP expression was associated with tumour progression and poor survival of gastric cancer $[15,16]$. However, the functional role of RKIP in gastric tumorigenesis remains largely unexplored.

In this study we performed experiments to investigate the role of RKIP in gastric cancer progression. Based on our preliminary results that RKIP expression is very low in gastric cancer cell line SGC7901, we reconstituted RKIP expression in SGC7901 cells by the transfection of RKIP expression vector and the selection of stable cell line by G418. Both RT-PCR and Western blot analysis confirmed the high expression of RKIP in pcDNA3.1(+)-RKIP/SGC7901 cells 

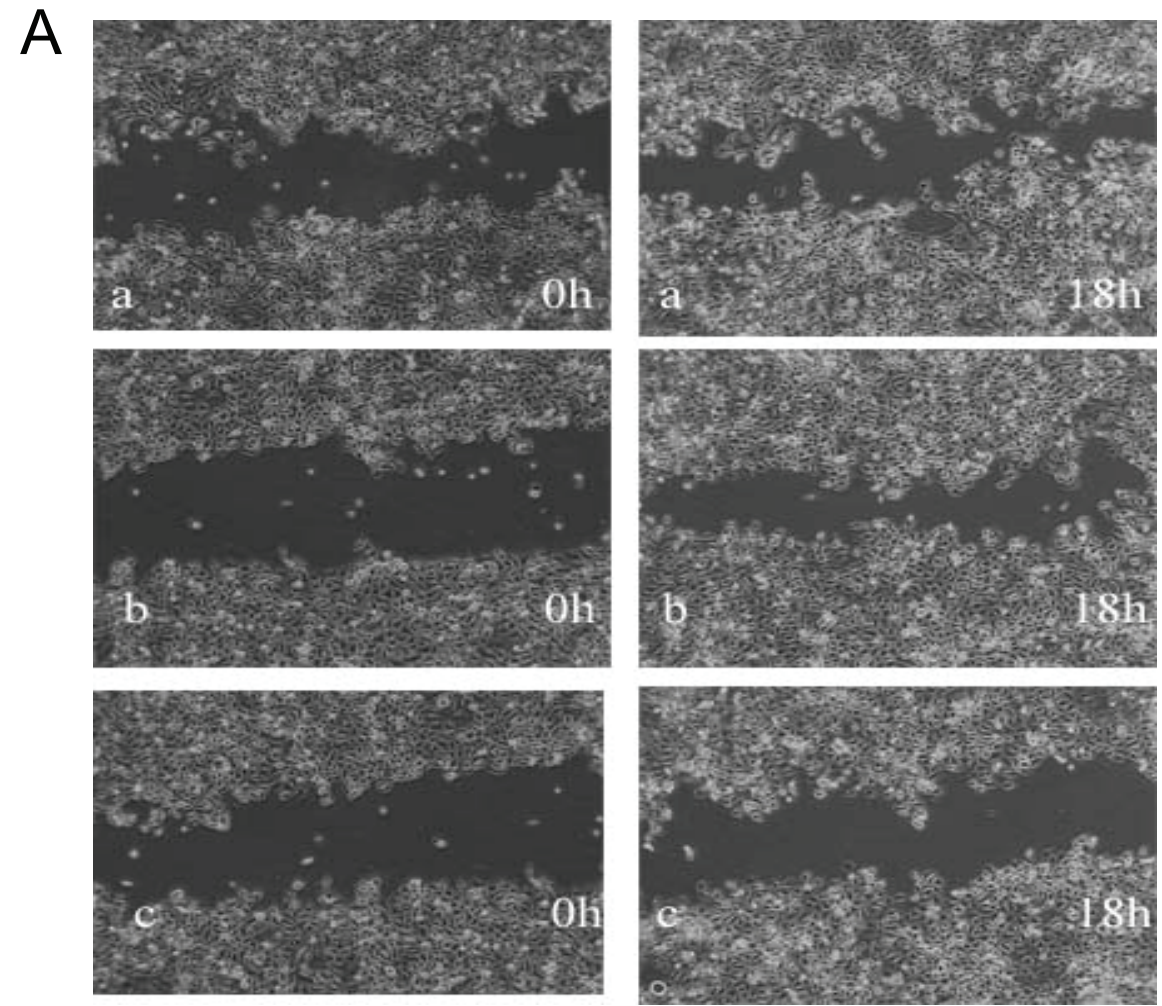

\section{B}
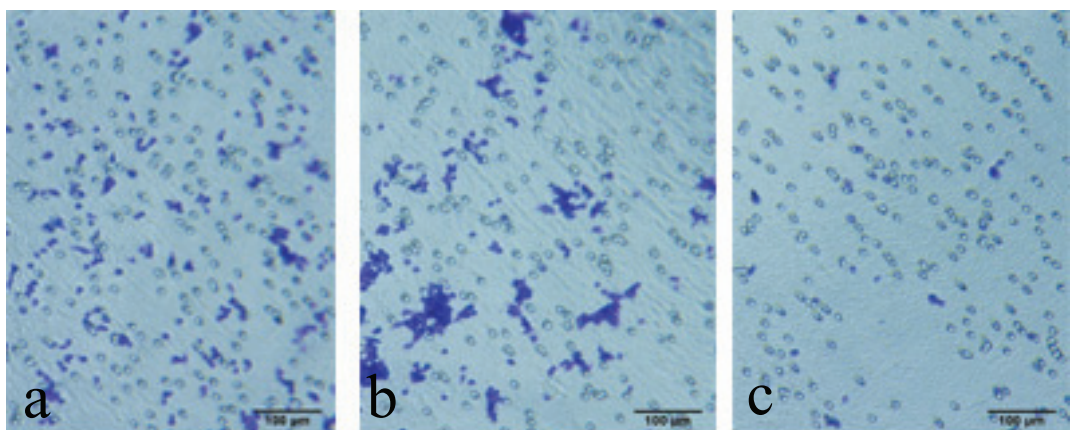

Figure 3. RKIP inhibits the migration and invasion of SGC-7901 cells. A. Wound healing assay showing higher migration ability of pcDNA3.1(+)RKIP/SGC7901 cells than that of pcDNA3.1(+)/SGC7901 and SGC7901 cells. Images were taken $0 \mathrm{~h}$ and $18 \mathrm{~h}$ after the scratches were taken on the cells with a 10 ul pipette tip. Magnification: 200x. B. Transwell invasion assay showing higher invasion ability of pcDNA3.1(+)-RKIP/SGC7901 cells than that of pcDNA3.1(+)/SGC7901 and SGC7901 cells. a. SGC7901 cells; b. pcDNA3.1(+)/SGC7901 cells; c. pcDNA3.1(+)-RKIP/SGC7901 cells. Scale bar: $100 \mu \mathrm{m}$. Shown were representative results from 3 independent experiments.

and the low expression of RKIP in pcDNA3.1(+)/SGC7901 and SGC7901 cells.

Next we characterized the biological phenotypes of SGC7901 and the derived cells. Our results showed that the reconstitution of RKIP inhibited the proliferation and clonogenicity of SGC7901 cells in vitro. Flow cytometry analysis showed that RKIP inhibited the cell cycle progression and induced the apoptosis of SGC7901 cells. These data suggest that RKIP inhibits the growth of gastric cancer cells by regulating cell cycle progression and apoptosis. Furthermore, by wound healing and in vitro invasion assay we demonstrated that the reconstitution of RKIP inhibited the migration and invasion of SGC7901 cells. Collectively, our in vitro data provide strong evidence that RKIP inhibits the malignant behaviors of gastric cancer cells.

To complement our in vitro findings with in vivo data, we injected SGC7901 and the derived cells into nude mice to induce xenografts. The analysis of the xenografts demonstrated that tumors developed more slowly and the weight of tumors was less in pcDNA3.1(+)-RKIP/SGC7901 cells derived 
A
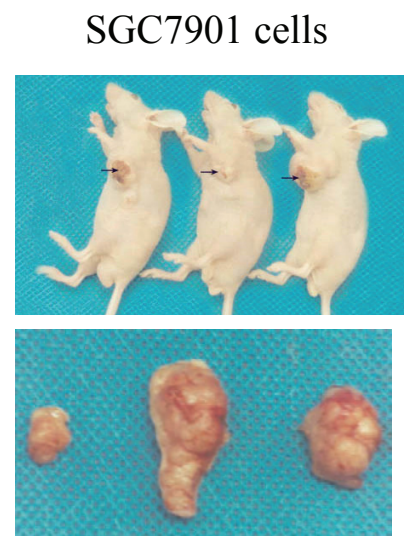

pcDNA3.1 $(+) /$ SGC7901 cells
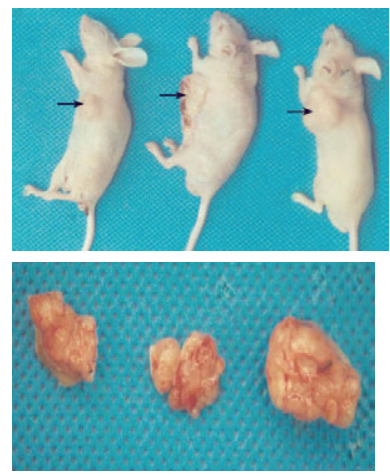

pcDNA3.1(+)-RKIP/

SGC7901 cells
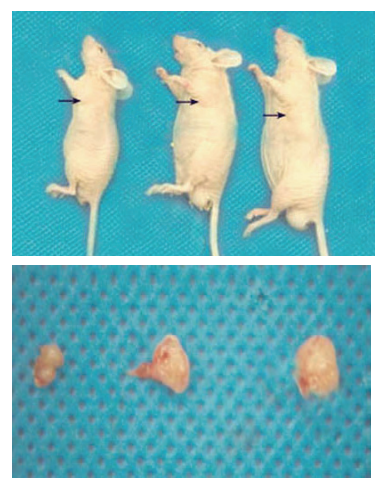

B

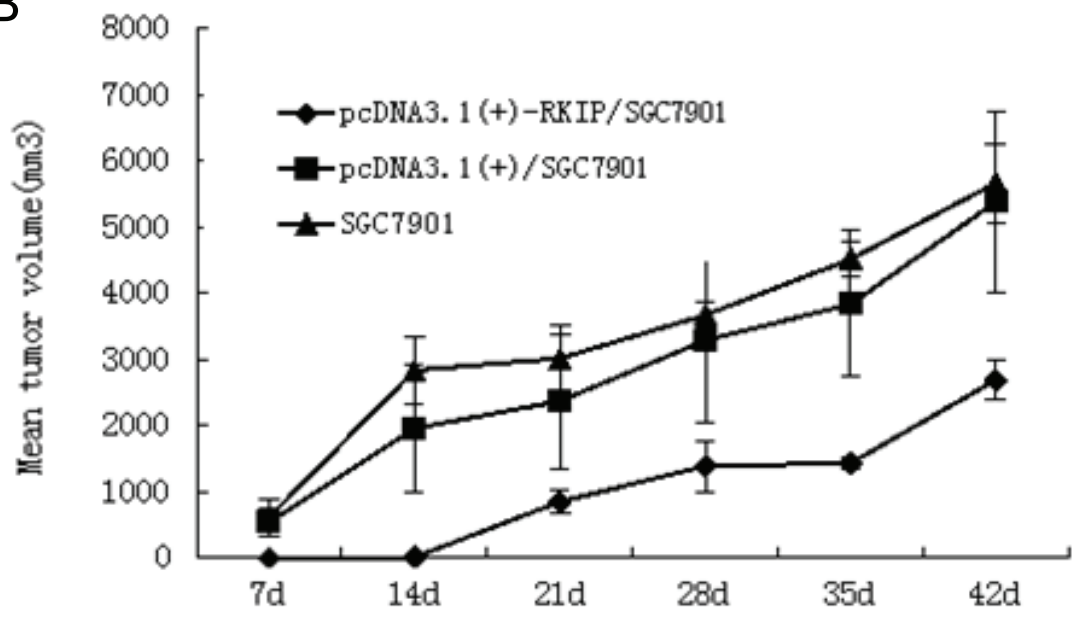

Figure 4 RKIP inhibits the growth of SGC7901 cells in vivo. A. Upper: three groups of nude mice were subcutaneously injected with SGC7901, pcDNA3.1(+)/SGC7901 and pcDNA3.1(+)-RKIP/SGC7901 cells, respectively; Lower: the tumor tissues dissected from the mice 6 weeks after the injection $(n=3)$. B. Tumor growth curves of xenografted SGC7901 cells in three groups $(n=3)$.

xenografts than in pcDNA3.1(+)/SGC7901 or SGC7901 cells derived xenografts. These in vivo data are consistent with the in vitro results and further confirm that RKIP performs tumor suppresser role in gastric cancer progression.

However, further studies are necessary to dissect the molecular mechanisms by which RIPK inhibits the malignant behaviors of gastric cancer cells. Chatterjee et al. reported that RKIP inhibited the activation of MAPK and NF- $\mathrm{KB}$ signaling to sensitize prostate and breast cancer cells to drug-induced apoptosis [17]. Park et al. showed that RKIP downregulated B-Raf activity to inhibit the transformation of melanoma [18]. Recently, it was shown that RKIP suppresseed the invasion and metastasis of breast cancer in part through a signalling cascade involving MAPK, Myc, LIN28, let-7, and downstream let-7 targets [19]. Thus we speculate that RIPK modulates several signaling pathways to regulate the proliferation, apoptosis and invasion of gastric cancer cells. In this aspect, it is important to identify the interaction networks of RKIP and our current work is focusing on the isolation and characterization of RKIP interacting partners by affinity purification and mass spectrometry, which will provide novel insights into the molecular mechanism of the tumor suppressor role of RKIP.

In summary, in this study our in vitro and in vivo data demonstrate that RKIP modulates the proliferation, apoptosis, migration, invasion and tumorigenicity of SGC7901 cells. These results reveal the tumor suppressor role of RKIP in gastric cancer and suggest that RKIP is a new therapeutic target for gastric cancer.

Acknowledgements: This work was supported by grants from National Natural Science Foundation of China (No. 3037153) and Science and Technology Bureau of Hunan Province (No. 2011FJ3022). 


\section{References}

[1] LEUNG WK, WU MS, KAKUGAWA Y, KIM JJ, YEOH KG, et al. Screening for gastric cancer in Asia:current evidence and practice. Lancet Oncol 2008; 9: 279-287 http://dx.doi. org/10.1016/S1470-2045(08)70072-X

[2] OOI CH, IVANOVA T, WU J, LEE M, TAN IB, et al. Oncogenic pathway combinations predict clinical prognosis in gastric cancer. PLoS Genet 2009; 5: e1000676. http://dx.doi. org/10.1371/journal.pgen.1000676

[3] YUAN W, CHEN Z, CHEN Z, WU S, GUO J, et al. Silencing of EphA2 inhibits invasion of human gastric cancer SGC7901 cells in vitro and in vivo. Neoplasma 2012; 59: 105-113. http://dx.doi.org/10.4149/neo 2012014

[4] DAI L, CHENG L, ZHANG X, JIANG Q, ZHANG S, et al. Plasmid-based STAT3-siRNA efficiently inhibits breast tumor growth and metastasis in mice. Neoplasma 2011; 58: 538-547. http://dx.doi.org/10.4149/neo 2011 $06 \quad 538$

[5] HUANG C, YANG G, JIANG T, ZHU G, LI H, et al. The effects and mechanisms of blockage of STAT3 signaling pathway on IL-6 inducing EMT in human pancreatic cancer cells in vitro. Neoplasma 2011; 58: 396-405. http://dx.doi.org/10.4149/ neo $2011 \quad 05 \quad 396$

[6] KELLER ET. Metastasis suppressor genes: a role for raf kinase inhibitor protein (RKIP). Anticancer Drugs 2004; 15: 663-669. http://dx.doi.org/10.1097/01.cad.0000136877.89057.b9

[7] YEUNG K, SEITZ T, LI S, JANOSCH P, MCFERRAN B, et al. Suppression of Raf-1 kinase activity and MAP kinase signalling by RKIP. Nature 1999; 401: 173-177. http://dx.doi. org/10.1038/43686

[8] ESCARA-WILKE J, YEUNG K, KELLER ET. Raf kinase inhibitor protein (RKIP) in cancer. Cancer Metastasis Rev. 2012 Jun 9. [Epub ahead of print] http://dx.doi.org/10.1007/ $\underline{\text { s10555-012-9365-9 }}$

[9] ZHANG ZQ, LI MY, ZHANG GY, PENG F, YAO HX, et al. Quantitative proteome analysis of clinical gastric adenocarcinoma using $18 \mathrm{O}$ stable isotope laeling and LCM. Prog. Biochem. Biophys 2009, 36(3): 311-322. http://dx.doi. org/10.3724/SP.J.1206.2008.00400

[10] MCCUBREY JA, STEELMAN LS, CHAPPELL WH, ABRAMS SL, WONG EW, et al: Roles of the Raf/MEK/ERK pathway in cell growth, malignant transformation and drug resistance. Biochim Biophys Acta 2007, 1773: 1263-1284.
[11] LI HZ, GAO Y, ZHAO XL, LIU YX, SUN BC, et al. Effects of raf kinase inhibitor protein expression on metastasis and progression of human breast cancer. Mol Cancer Res 2009; 7: 832-840. http://dx.doi.org/10.1158/1541-7786.MCR-08$\underline{0403}$

[12] ZLOBEC I, BAKER K, MINOO P, JASS JR, TERRACCIANO $\mathrm{L}$, et al. Node-negative colorectal cancer at high risk of distant metastasis identified by combined analysis of lymph nodestatus, vascular invasion, and raf-1 kinase inhibitor protein expression. Clin Cancer Res 2008, 14: 143-148. http://dx.doi. org/10.1158/1078-0432.CCR-07-1380

[13] NOTARBARTOLO M, GIANNITRAPANI L,VIVONA N, POMA P, LABBOZZETTA M, et al. Frequent alteration of the Yin Yang 1/Raf-1 kinase inhibitory protein ratio in hepatocellular carcinoma. OMICS 2011; 15: 267-272. http://dx.doi. org/10.1089/omi.2010.0096

[14] LI HZ, WANG Y, GAO Y, SHAO J, ZHAO XL, et al. Effects of raf kinase inhibitor protein expression on metastasis and progression of human epithelial ovarian cancer. Mol Cancer Res 2008; 6: 917-928. http://dx.doi.org/10.1158/1541-7786. MCR-08-0093

[15.] WANG J, YANG YH, WANG AQ, YAO B, XIE G, et al. Immunohistochemical detection of the Raf kinase inhibitor protein in nonneoplastic gastric tissue and gastric cancer tissue. Med Oncol 2010, 27: 219-223. http://dx.doi.org/10.1007/s12032009-9194-Z

[16] FUJIMORI Y, INOKUCHI M, TAKAGI Y, KATO K, KOJIMA $\mathrm{K}$, et al. Prognostic value of RKIP and p-ERK in gastric cancer. J Exp Clin Cancer Res 2012 Mar 31; 31: 30. http://dx.doi. org/10.1186/1756-9966-31-30

[17] CHATTERJEE D, BAI Y, WANG Z, BEACH S, MOTT S, et al. RKIP sensitizes prostate and breast cancer cells to druginduced apoptosis. J Biol Chem 2004; 279: 17515-17523. http://dx.doi.org/10.1074/jbc.M313816200

[18] PARK S, YEUNG ML, BEACH S, SHIELDS JM, YEUNG KC. RKIP downregulates B-Raf kinase activity in melanoma cancer cells. Oncogene 2005; 24: 3535-3540. http://dx.doi. org/10.1038/sj.onc. 1208435

[19] DANGI-GARIMELLA S, YUN J, EVES EM, NEWMAN M, ERKELAND SJ, et al. Raf kinase inhibitory protein suppresses a metastasis signalling cascade involving LIN28 and let-7. EMBO J. 2009; 28: 347-358. http://dx.doi.org/10.1038/ emboj.2008.294 